\title{
A Survey on the Current Situation of Classroom Teaching Methods and Teacher-Student Relationships in Chinese Universities
}

\author{
Hong-ling GUO \\ Public Administration and Law School, Southwest Jiaotong University, Chengdu,China,610031 \\ Corresponding author.Email: hlg@swjtu.edu.cn
}

\begin{abstract}
The purpose of this paper is to examin undergraduates' views on classroom teaching methods and student- teacher relationgships in Chinese Universities. 420 undergraduates from four universities in Western China were investigated by semistructured interview and questionnaire. Results indicate $85 \%$ the participating undergraduates $(n=420)$ reported current classroom teaching methods(Multi-ple choices are allowed)in universiries ma-inly are traditional"Teachers teaching and students listening" and "ask questions occasionally".Some new tea- ching models are not widely used,such as "Experiential teaching;discussion;project-based teaching.The surveyshows only $31.4 \%$ of the participating undergraduates were satisfied with the current teacher-student relation-ships in the universities. $71.5 \%$ of them thought the current teacher-student relationship needs to be improved.Students who choose new teaching methods are $23.3 \%$ more satisfied with the current teacher-student relationship than those who only choose traditional teaching methods. It can be seen that the use of new teachingmethods can improve student-teacher relationships. And the undergraduates understood the current problems of the teacher-student relationships, They expect tobuild a harmonious, cooperative, mutual understanding and tolerant teacher-student relationships.The findings of this study can provide a reference for improving class--room teaching methods and teacher-student relationships in Chinese universities.
\end{abstract}

Keywords:Teacher-student Relationships, classroom teaching methods, undergraduates, Chinese universities.

\section{INTRODUCTION}

With the development of internet technology, new teaching modes such as MOOC (massive open online courses), FC (flipped classroom), SPOC (small private online course) and BL (blended learning) have become hot topics in the educational field in recent years. With the popularity of online courses, students have more diverse ways to acquire knowledg in universities. They rely less and less on teachers.The traditional teacher-centered teaching activities are gradually replaced by student-centered ones.In the process of school education practice, the conflict and opposition trend of the teacher-student relationships is becoming more and more obvious. [1] UNESCO (The United Nations Educational, Scientific and Cultural Organization) thinks that teacher-student relationship is the core of the education process.[2] Research has shown that the teacher- student relationships are good to improve students' study motivation,academic achievement, emotional and social development, engagement, investment of students in their studies and growth [3][4].And good student-teacher relationships can also increase teachers' job satisfaction, ease their stress at work, reduce teachers burnout, enhance, work passion [5][6]. But In internet era, intellectual authority position of teacher is on the wane, the student-teacher relationship emerged some new feature and problems[7]. Some researchers examined on student- teacher relationship in the middle schools and primary school[8][9], and the supervisor-students relationship in universities[10]. But few literatures pay attention to undergraduates' perceptions of calssroom teaching methods and influence on the student-teacher relationships in universities .

This paper examined 420 undergraduates' perceptions on classroom teaching methods and teacher- 
student relationship from 4 Chinese universities. we mainly focused on the following research questions:

(1) Current classroom teaching methods in universities, especially the use of new teaching methods; (2)Undergraduates' views on the current relationship between teachers and students;(3)Does the adoption of new teaching methods help to improve the relationship between teachers and students?

\section{METHODOLOGY}

Methodology was based on interviews and questionnaires for data collection. Due to the limitation of space, this article mainly presents the investigation and results of the qualitative questionnaires. The target population was undergraduates in universities in Western China.

\subsection{Procedure and Instruments}

Firstly, we conducted face-to-face semi-structured interviews with 50 undergraduates. They were asked to express their views on three aspects: (1) teaching methods: including in Main teaching methods and students' preferences (2)student-teacher relationship: including in Students' satisfaction with the current teacher-student relationship; the main problemsin student-teacher relationship; ideal teacher-student relationship;(3) The connection between the adoption of new teaching methods and the improvement of teacher-student relationships.

Secondly, we constructed an exploratory questionnaire according to the interview results. The qualitative questionnaire covers 9 questions in the above three aspects.

Thirdly, data collection process. Data was collected during March - May 2019.With the help of the teacher, 4 undergraduates used their spare time to participate in the distribution and recovery of the questionnaire to four universities in Sichuan.

\subsection{Population}

Altogether, 420 undergraduates participated in this study. They were between 17-23 years of age $(M=20$, $\mathrm{SD}=1.8)$. There were 189 females $(45 \%)$ and 231 males (55\%). Participants were from four grades in four universities (Southwest Jiaotong University; Sichuan University; University of Electronic Science and Technology of China;Southwest University of Finance and Economics)in Sichuan in order to maximize reachout for varied participants.

\section{FINDINGS}

\subsection{Teaching methods}

According to our interviews with 50 undergraduates, the main classroom teaching methods in universities include the traditional teaching method ( "teachers speak and students listen"and"ask questions occasionally")and new teaching methods including in "Experiential teaching"; discussion;project-based teaching,other". The survey results show 85\%(357 of 420) the participating undergraduates reported current classroom teaching methods(Multiple choices are allowed) in universiries mainly are traditional.Among the new teaching methods, the discussion method is applied more(88 of 420).(see frigure 1)

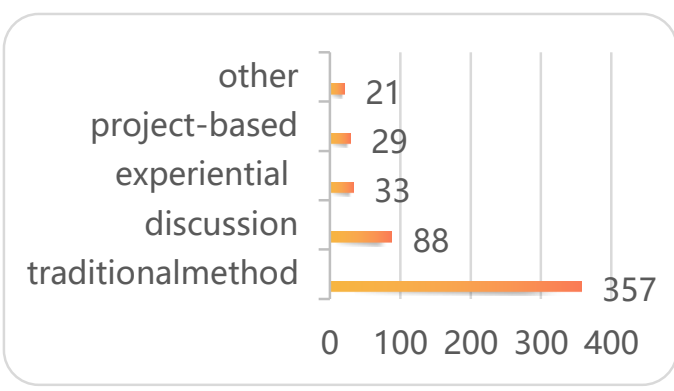

Fig1 The main classroom teaching methods in Universities

When we asked undergraduates which of the above methods they prefer , $41 \%$ of them chose traditional teaching methods. $16 \%$ chose "discussion".(see fig.2)

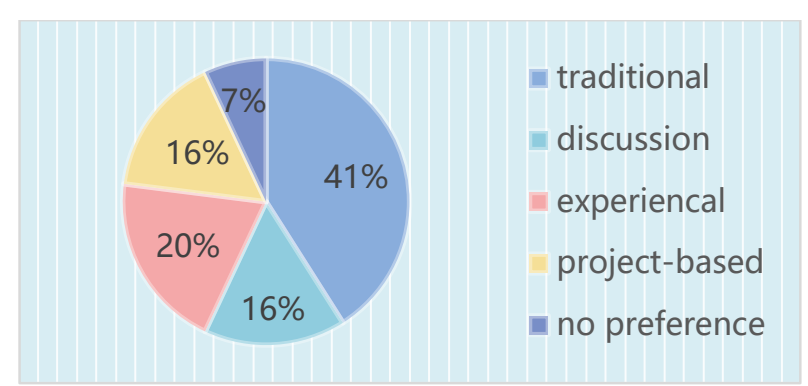

Fig2.Classroom teaching methods preferred by undergraduates

\subsection{Teacher-student relationships}

This part mainly investigated undergraduates' evaluation and expectation of teacher-student relationships.

Firstly, we asked the participating undergraduates whether they were satisfied with the current teacherstudent relationships. Only7.4\%\% responded with a "Very satisfied",23\% responded with a "satisfied"; $24 \%$ responded with a "somewhat dissatisfied"; $6.9 \%$ responded with a "Very dissatisfied". (see fig. 3) 


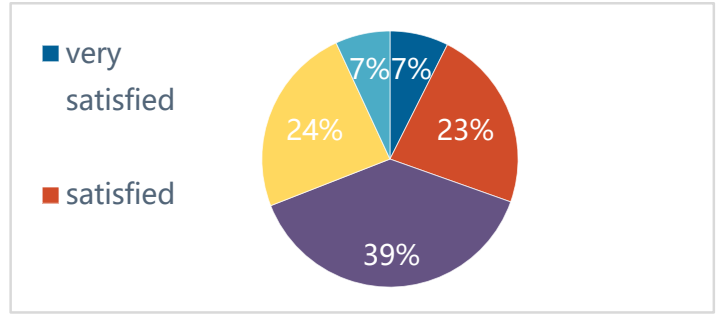

Fig. 3 Feelings on the current teacher-student relationship

When the participating undergraduates were asked "What do you think are the obstacles affecting the relationship between teachers and students(Multiple choices are allowed)",the top three are (1)81\% thought "lack of communication between teachers and students";(2) $62 \%$ thought "the universal instrumental rationality in the teacher-student relationship";(3)49\% thought "under the impact of new media and online classes, teachers' authority is reduced". While our questionnaire survey also showed $44.3 \%$ of the participating undergraduates responded " go to class for credits"; $84.7 \%$ don't turn to teachers when they have problems..

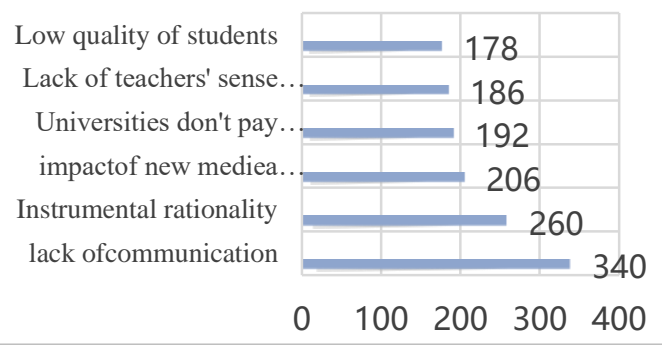

Fig. 4 the obstacles affecting the student-tteacher relationships

Secondly,we investigated undergraduates' expectation to teacher-student relationships. When the participating undergraduates were asked whether they think the teacher-student relationship needs to be improved, $25 \%$ of participating undergraduates responded with a " highly necessary"; $46.5 \%$ "necessary"; $19.3 \%$ responded with "don't care"; $8.6 \%$ responded with "not necessary" and " not necessary at all". (see fig. 5)
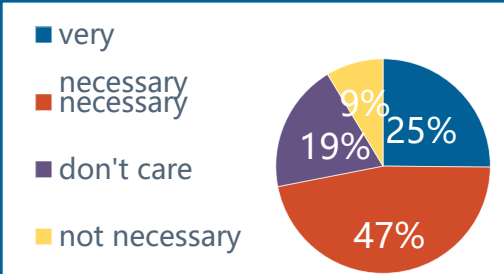

Fig.5 The necessity of improving the relationship between teachers and students
And our questionnaire survey also show the ideal teacher-students relationships,in the eyes of undergraduates, were harmonious, mutual aid and cooperation, mutual understanding and tolerance.

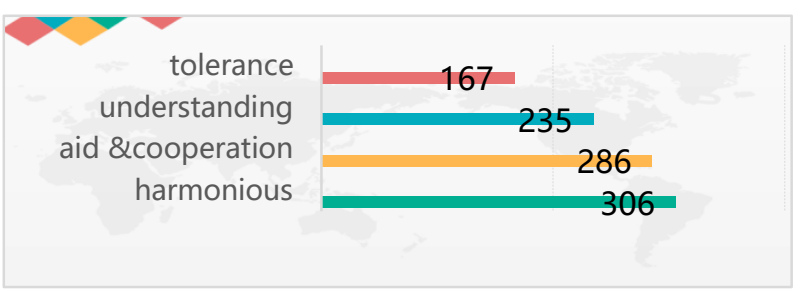

Fig.6 Ideal teacher-student relationship expected by undergraduates

They believe that teachers should play the following role in the relationships between teachers and students: knowledge imparters, role models, life mentors, intimate friends, supporters of learning.

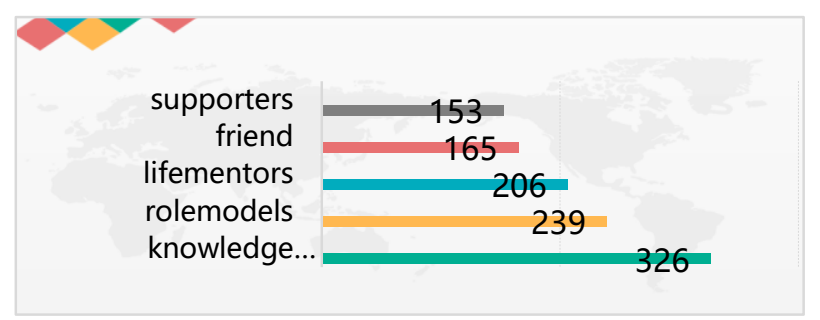

Fig.7 The role of teachers expected by undergraduates

\subsection{The connection between new teaching methods and the teacher-student relationships}

With the popularity of online courses, some new classroom teaching methods appear accordingly. These methods pay more attention to the needs of students.Is the adoption of new classroom teaching methods conducive to the improvement of the relationship between teachers and students? Our questionnaire survey showed $39 \%$ of the participating undergraduates answered "yes";26\% answered "no"; $35 \%$ answered "uncertain". Students who only choose traditional teaching methods and at least one new teaching method are compared and analyzed, the latter is $23.3 \%$ more satisfied with the current teacher-student relationship than the former.

\section{CONCLUSIONS}

With the rapid development of the Internet,the status and function of teachers have changed in teaching activities, which led to indifferent and lack of trust relationships between teachers and students. [11]At the same time, the popularity of online courses has also brought about the improvement of college classroom teaching methods. Some new student-centered teaching methods, such as project-based teaching methods and experiential teaching methods, have been adopted.Can 
these new teaching methods promote the relationship between teachers and students in universities?

In this study, we explored undergraduates' perceptions on classromm teaching methods and studentteacher relationships in universities. According to our research, we can draw the following conclusions:

(1) The survey shows that the current college classroom teaching still focuses on the traditional teaching methods of "teachers speaking and students listening",however, some new student-centered teaching methods,such as experiential teaching \group discussion\ project-based teaching and autonomous learning, have emerged. Compared with traditional teaching methods, $52 \%$ of undergraduates prefer to new teaching methods.

(2) Most undergraduates are not satisfied with the current teacher-student relationship and think it is necessary to improve it. Only $30.4 \%$ of the participating undergraduates, and $71.5 \%$ of them thought it needs to be improved.They thought the main obstacles affecting the relationship between teachers and students were " lack of communication", "the universal instrumental rationality", "the impact of new media and online classes", “university don't pay attention to it" "lack of teachers'sense responsibility", "low quality of students". They expect to build a harmonious, cooperative, equal, mutual understanding and tolerant relationships between teachers and students. So to improve teacher-student relationship, teachers and students need to make joint efforts to undertake their own roles and responsibilities.

(3) Adopting a new student-centered classroom teaching method will help to improve the relationship between teachers and students. The new teaching method pays more attention to the needs of students and can strengthen the communication between teachers and students.

Based on our research results, we suggest that future research on this topic can include broader and more diverse samples from different countries and regions, as well as different types of social networking sites. And it is necessary to understand teachers' views on this topic. More importantly,we need to focus on how to improve classroom teaching methods to adapt to the changing educational environment.

Of course, this study is not without limitations. Firstly, the research samples are non random samples from four universities in Chengdu. Maybe the situation of universities in other regions is different. Secondly this study was conducted in China, maybe in other some countries, under different cultural circumstances and educational policies the results may be biased. In addition, our data was collected during March - May 2019. COVID-19 have an enormous impact on the world, which is changing Classroom teaching modes and communication ways between teachers and students in Universities.Maybe after COVID-19, data was collected can be different.

\section{REFERENCES}

[1] WANG Deng deng, YUAN Liqin, The Review of Ten Years'Domestic Research on the Relationship Between College Teachers and Students, Heilongjiang Researches on Higher Education, (2016), 262 (2) 97-101.(in Chinese)

[2] Donghui, Hao; From Displine to Communi ca tion: Reflections on the Reconstruction of teacher-student relationships ,Knowledge Cultures; Woodside Vol. 7, Iss. 1, (2019): 44-48.

[3] Ridwan Maulana,Teacher student interpersonal relationships do change and affect academic motivation: [J],British journal of educational psychology,2010,80(2),199-221.

[4] Debora Roorda,Suzanne Jak,etc. Affective TeacherStudent Relationships and Students' Engagement and Achievement: A Meta-Analytic Update and Test of the Mediating Role of Engagement. [J]School psychology review 2017,46(3):1-23.

[5] Bo Shen,Nate Mc Caughtry,Jeffrey Martin,Alex Garn,Noel Kulik, Mariane Fahlman,The relationship between teacher burnout and student motivation ,British Journal of Educational Psychology (2015), 85, 519-532.

[6] Shiri Lavy , Shira Bocke,A Path to Teacher Happiness?A Sense of Meaning Affects TeacherStudent Relationships, Which Affect Job Satisfaction J Happiness Study (2018) 19:14851503.https://doi.org/10.1007/s10902-017-9883-9.

[7] Gehlbach, H., Brinkworth, M. E., \& Harris, A. D. (2012). Changes in teacher-student relationships. British Journal of Educational Psychology, 82, 690-704.

[8] David Dennie, The impact of teacher student relationships and classroom engagement on student growth percentiles of 7 th and 8th grade students [J]Psychology in the Schools,201956(5),765-780.

[9] Susanna Pallini,Giovanni Maria Vecchio,ect. Student-Teacher Relationships and Attention Problems in School-Aged Children: The Mediating Role of Emotion Regulation [J]School Mental Health,2018,12(8):12-28.

[10] Yu Xiaomin, Zhao Jinru, Wu Xin.Empirical Analysis on the Status and Influence of the Supervisor-Students Relationship in Universities.J Tianjin university,(2017)19(2),157-162. (in Chinese) 
[11] Wang Changhua, Jin Yu, Geng Gretchen. On the Teacher-Student Relationships andTeachers' Nonverbal Immediacy.Journal of National Aca-demy of education Administration, (2017) (2) 63-71. 